\title{
DECISION-MAKING MODELS FOR INTEROPERABLE LEAN, AG ILE, RESILIENT AND GREEN SUPPLY CHAINS
}

\author{
Izunildo Cabral \\ UNIDEMI, Faculdade de Ciên cias e Tecnologia \\ Universidade Nova de Lisboa, Portugal \\ E-mail: $\underline{\text { i.cabral@fct.unl.pt }}$ \\ Pedro Espadinha-Cruz \\ UNIDEMI, Faculdade de Ciên cias e Tecnologia \\ Universidade Nova de Lisboa, Portugal \\ E-mail: p.cruz@fct.unl.pt \\ Antonio Grilo \\ UNIDEMI, Faculdade de Ciên cias e Tecnologia \\ Universidade Nova de Lisboa, Portugal \\ E-mail: acbg@fct.unl.pt
}

\author{
Rogerio Puga-Leal \\ UNIDEMI, Faculdade de Ciên cias e Tecnologia \\ Universidade Nova de Lisboa, Portugal \\ Virgilio Cruz-Machado \\ UNIDEMI, Faculdade de Ciên cias e Tecnologia \\ Universidade Nova de Lisboa, Portugal
}

\begin{abstract}
Supply Chain Management (SCM) is crucial to be present in global markets as nowadays competition is between supply chains rather than between companies. Current SCM paradigms like Lean, Agile, Resilient, and Green (LARG) are usually presented as individual management philosophies. The current challenge is to make the supply chain more competitive, capable of responding to the demands of customers in a market increasingly volatile and turbulent with agility, in conjunction with environmental responsibilities, and the necessity to eliminate processes that add no value. Organizations must implement a set of LARG Practices that will have impacts in the SC's competitiveness. The choice of which LARG practices are adequate is a complex problem to managers in the SC. Moreover, as many of these practices will be implemented crossing companies' individual boundaries, it is important to analyze how interoperable they are in order to guarantee successful deployment.

This paper presents two models to support decision-making relating LARG Practices and their interoperability. With the ANP model the objective is to select the best LARG Practices to be the SC competitiveness; and the AHP model seeks to rank LARG Practices according to their interoperability levels. The models have been theoretically validated by experts and there is an ongoing process of real data validation.
\end{abstract}

Keywords: Lean, Agile, Resilient, Green, Supply Chain Management, Interoperability, AHP, ANP

\section{Introduction}

The global market has imposed that competitiveness improvement requires collaborative work and partnerships across supply chains, motivating companies to look for enhanced interoperability between computer systems and applications (Jardim-Goncalves et al, 2006; Huhns et al, 2002). In complex networks, supply chains management requires adequate methodologies as an inefficient decis ion-making by one agent may bring severe consequences to other agents, with negative outcome in the cost, time to market, quality and service on the final product.

The main objective of this paper is to present two models that may contribute to assist managers to select the most adequate Supply Chain Management (SCM) Practices and metrics (KPI's) according to Lean, Agile, Resilient, and Green (LARG) paradigms, considering Interoperability requirements. The proposed and described models are outputs of a three years joint project between FCT-UNL (Portugal) and MIT (USA). The paper is organized in the 4 sections. Firstly, it is presented a brief review about the Lean, Agile, and Resilient and Green (LARG) Supply Chain Management (SCM) paradigms. In the following section it argued about the need for addressing the interoperability dimension. In third section, an ANP model is proposed to select the best practices and metrics to be implemented in SCM. In the last section, it is discussed how a AHP model may contribute to evaluate the interoperability of LARG practices. Finally, some considerations are drawn about current research work results and future work. 


\section{Lean, Agile, Resilient and Green SCM Paradigms: A Review}

The developments of new management methodologies applied to SCM leads to a change of ideas and impose modifications in the way of managing inventories. Associated to these changes, IT must develop at high speed new networked platforms that assist easily the SCM accordingly to the business model.

According to (Womack, Jones, \& Ross, 1991), Lean is an approach which provides a way to do more with less (e.g., less human effort, less equipment, less time and less space), while coming closer to customer requirements. The basic principles in the lean paradigm is waste elimination (Agarwal et al, 2006) and cost minimization. To (Azevedo, Carvalho, and Machado, 2010) the Lean paradigm is a systematic approach to identify and eliminate all non-value-added activities through continuous improvement, in order to fulfill customers need and maintaining profits. The Agile Manufacturing concept focuses essentially on the ability to respond rapidly to changes in demand, both in terms of volume and variety. The origins of Agility as a business concept lie in Flexible Manufacturing Systems (FMS) (Fan et al, 2007). The Agility strategy paradigm a ims to create the ability to respond rapidly and at cost effectively to unpredictable changes in markets and increasing levels of environmental turbulence (Agarwal et al, 2007). According to (Baramichai et al., 2007), an Agile supply chain is an integration of business partners to enable new competencies in order to respond to rapidly changing, continually fragmenting markets. Resilience refers to SC's ability to cope with unexpected disturbances (Azevedo, et al, 2010). Supply chain resilience is concerned with the system ability to return to its original state or to a new more desirable state, after experiencing a disturbance, and avoiding the occurrence of failures modes (Reichhart and Holweg, 2007). According to (Azevedo et al, 2010), in a Resilient SC's system, the purpose is to react efficiently to the negative effects of disturbance, that can be more or less severe. It is important to note that Resilience is not always desirable, for instance, if an organization strategy is to be lean, reducing inventory cost, they must have a low inventory level, which makes it less resilient.

Environmentally sustainable green supply chain management has emerged as organizational philosophy to achieve corporate profit and market share objectives by reducing environmental risks and impacts while improving ecological efficiency of these organizations and the ir partners (Rao and Holt, 2005). (Srivastava, 2007) defined green SCM as "integrating environmental thinking into SCM, including product design, material sourcing and selection, manufacturing processes, delivery of the final product to the customers as well as end-of-life management of the product after its useful life". According to (Srivastava, 2007), green supply chain management can reduce the ecological impact of industrial activity without sacrificing quality, cost, reliability, performance or energy utilization efficiency; meeting environmental regulations to not only minimizing ecological damage, but also leading to overall economic profit.

The tradeoffs between Lean, Agile, Resilient, and Green Supply Cha in Management paradigms must be understood to help companies and supply chains to become more efficient, streamlined, and sustainable. To this end, it is necessary to develop a deep understanding of the relationships (conflicts and commitments) between the lean, agile, resilient and green paradigms, exploring and researching their contribute for the sustainable competitiveness of the overall production systems in the supply chain, measured by its Cost, Lead Time, Quality and Service Level (Carvalho and Machado, 2010).

\section{Business Interoperability}

From a technical perspective, interoperability is a capability to exchange information homogeneously between business partners, understand the data and process it, in a seamless manner. This initial concept defined by (Berre et al, 2005) considers interoperability as "the ability of two or more systems or components to exchange information and to use the information that has been exchange". In contrast, from a business perspective, interoperability is concerned with forming innovative networks of value creation and defining new ways of collaboration with partners and implementing collaborative bus iness processes. In this point of view, a re-definition of the concept of interoperability as been emerging as "the organizational and operational ability of an enterprise to cooperate with its business partners and to efficiently establish, conduct and develop IT-supported business relationships with the objective to create 
value." (Legner and Wende, 2006). For example, in an automotive supply chain, Original Equipment Manufacturers (OEM) need to be coordinated with industry participants, such as suppliers (raw materials and component providers) and distributors. Heterogeneous growth of the Supply Chain in space, due to geographic and economic issues can occur, but managers cannot afford of having heterogeneously loose information or let it be retained by space boundaries. So, these companies must coordinate their activities to ensure that their activities are compatible and information flows seamlessly through the supply chain. Interoperability issues in automotive industry are a crucial subject, because of the complexity of the product, the design process, and the high complexity of their supply chains that may lead to the magnification of the effect of interoperability problems along the SC. The requirements of interaction inside and outside of a company becomes acute when there is a need to exchange information, transact and when we need to collaborate to specific objectives. These three main areas are where a company needs to interact and are the focus of interoperability problems, and that it is why the concept has grown into a more comprehensive and wider issue. According to (ATHENA, 2006), these primary functions are inherent to any company's activity and require different levels of interoperability. When different companies interact with each other, beyond technical issues, like Information Systems infrastructure and Semantics, activities require also an appropriate management of external relationships; they have to deal with employees and their culture values; and also to define collaborative scenarios adequate to business processes. Within the companies, subjects as business strategy, organizational structures and IPR management are the main interoperability areas in which we must attend to develop and improve business process models and its correspondent information system.

\section{Selecting LARG Best Practices for Supply Chain Management}

Supply Chains are structured networks involving suppliers, manufacturers, distributors, retailers, and final customers. Within the Supply Chain there are complex decision-making involving all the actors with the overall objective of turning supply chains more competitive. Within this research work the main objective is to examine the potential of ANP model in helping managers to select the Lean, Agile, Resilient and Green best practices to be implemented. ANP was selected due to the following facts: (i) supply chains are complex networks with feedback and interdependence relationships within their actors; (ii) there are KPIs and Practices that can be used by one or more actor; the same KPI or practice can be used in different way in different level of the supply chain; (iii) some Practices can have direct influence in one or more enabler criteria (Cost, Service Level, Lead Time, Quality of product); (iv) Practices may have contradictory results, like sometimes in order to be more Lean an entity must be less Resilient. For example, if the practice is "reduction of inventory level", the entity will be more lean (reduction of inventory cost) and less resilient (no inventory stock to respond to an eventually disruption). Figure 1 shows the ANP model developed to support decision-making.

In this model, relationships established between the KPI's, Practices and the Stakeholders of the SC are condensed in a five cluster structure, where the LARG KPI's are structured in a Criteria and Sub-criteria clusters, and the LARG Practices in the Alternatives cluster. The actors that will be inquired (Supplier, Focal Firm and Distributor) are annexed in Stakeholders cluster. All the clusters are connected by six dependencies and by two inner dependencies.

(1) $\mathrm{SC}$ competitiveness - this cluster refer to the objective of the SC. A supply chain must be competitive to survive in the global market. 


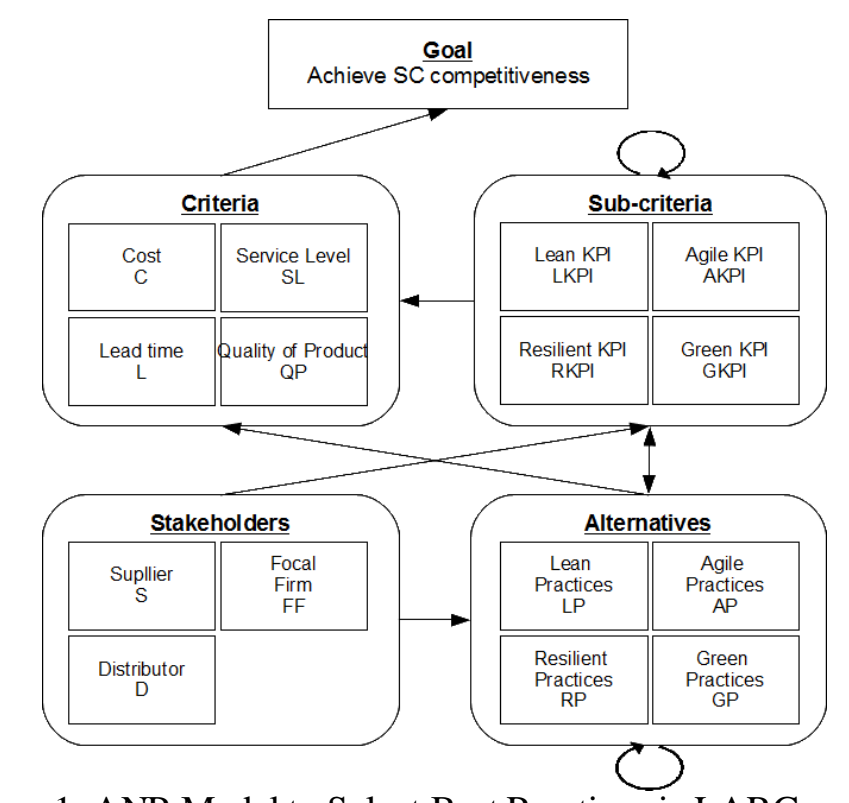

Figure 1. ANP Model to Select Best Practices in LARG context.

(2) Criteria (enablers) - There are four main enabler criteria to assess the supply chain performance that have been included as nodes of this cluster. Each enabler will contribute to measure the SC's performance, and a pairwise comparison is conducted between them to assess the relative importance of the criteria with respect to the goal (SC competitiveness). The connections to the goal cluster mean that these four criteria to evaluate the SC's performance will be used.

(3) Sub-criteria (KPIs) - This cluster contains the KPIs that can be used to measure the enablers criteria. They are organized by paradigms (Lean, Agile, Resilient, and Green). An inner dependency among the elements of this cluster has also been included, meaning that are some KPIs that can be used to one or more paradigm.

(4) Stakeholders (Entities) - In this cluster there are three nodes (Supplier, Focal Firm, and Distributor). It is considered that they are the major agents in the SC. Pairwise comparisons between these nodes can be made to assess which entity is more or less important to be the supply chain in a LARG context. The connections with the practices mean that will be the practices implemented by each entity that will contribute to improve the KPIs value and consequently the enabler's criteria.

(5) Alternatives (Practices) - This cluster includes the set of Practices (grouped by paradigms) that can be implemented by the entities in the supply chain. The inner dependency indicates that some Practices belong to one or more paradigm. For example, reduction of waste is a practice that is Lean and Green at the same time.

\section{Evaluate and Establish Interoperable Practices}

While some LARG Practices focus only within the companies' boundaries, there are some practices that will require the design of an adequate inter-organizational information system, with the definition of common standards and synergies. The analysis of the interoperability between the manufacturer (focal firm) and the other agents within the SC becomes an important issue for the success of LARG Practices deployment. The Business Interoperability analysis will provide an identification of where the main obstacles are located, which practices are more adequate according to the level of interoperability required and where to act and model correctly the business process and information requirements. Hence, a decision model was created to analyze existing interoperability issues and, then, cross that interoperability issues for the establishment of prioritized practices that should be applied to a SC in a LARG context. In order to analyse interoperability and determine the interoperable practices, the model is 
divided in two parts: the first part (Criteria and Sub-criteria) has the intention of gauging interoperability parameters according to the current activities of the focal firm and its industry partners; the second part (Alternatives) is to cross-link the weighted parameters with the LARG Practices.

The first part of the AHP model that constitutes the criteria and sub-criteria is based on ATHENA's Business Interoperability Framework (ATHENA, 2006), where it is established that the main areas that are afected by interoperability are: Business Strategy $\left(\mathrm{C}_{1}\right)$; Organizational Structures $\left(\mathrm{C}_{2}\right)$; Employees and Work Culture $\left(\mathrm{C}_{3}\right)$; Collaborative Business Process $\left(\mathrm{C}_{4}\right)$; Management of External Relationships $\left(\mathrm{C}_{5}\right)$; IPR Management $\left(\mathrm{C}_{6}\right)$; Business Semantics $\left(\mathrm{C}_{7}\right)$ and Informations System $\left(\mathrm{C}_{8}\right)$. These key areas are the focus of the model, and are considered to be Interoperability Parameters for this model.

As Sub-criterias for the decision model it uses the expanded interoperability parameters defined by (Zutshi, 2010), that act according with existing interoperability frameworks, and refers to general aspects of interoperability applied to most of the existing business. These parameters are marked in Figure 2 as Sub-Criteria.

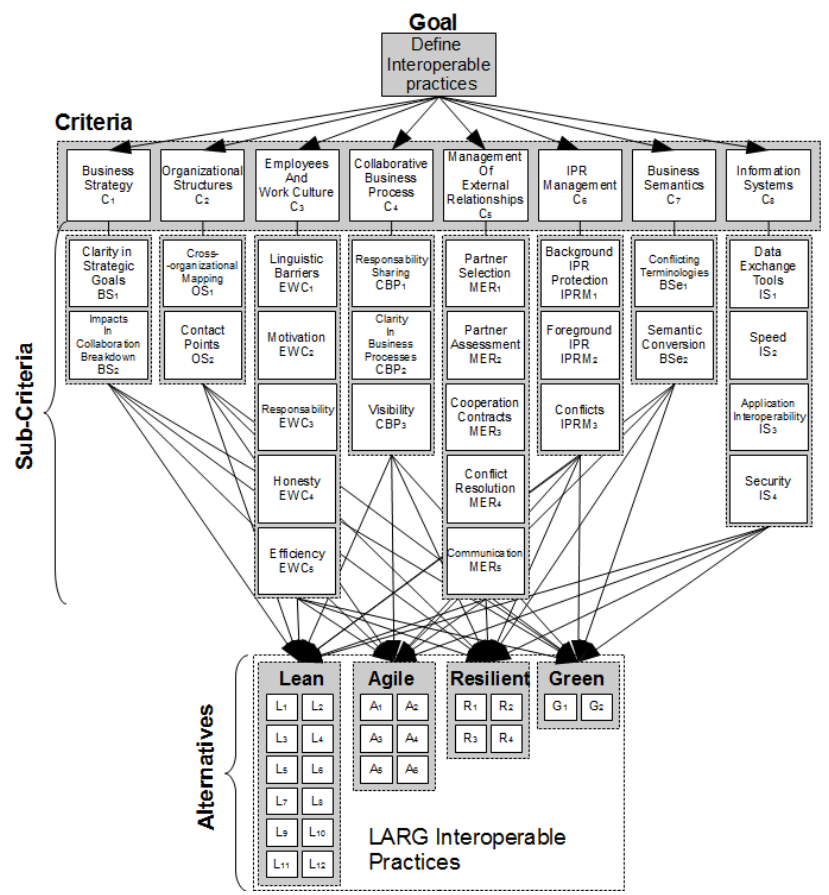

Figure 2. Interoperability Evaluation of LARG Practices with a AHP Selection Model.

This set of Criteria and Sub-criteria will allow, by making pairwise comparisons, to see how much more relevant are the indicated parameters in terms of interoperability inside of each company, using a fundamental scale, which lies between "equal importance" to "extreme importance" (Saaty, 1980). Hence, by making these comparisons, it is possible to obtain scores for each parameter and determine its relevance in each SC sectors to evaluate overall interoperability and compare different points of view from the actors.

The second step of the analysis will consist in the evaluation of the SC practices. From the previously established practices inherent to Lean, Agile, Resilient and Green were selected the ones that involve cooperation, i.e., the practices that are susceptible to have interoperability issues. Using the same principle as before, LARG Practices will be prioritized and then crossed with the score from the interoperability parameters and then obtain the final judgment about which LARG Practices are the most interoperable.

It is noteworthy that this AHP model is to be applied to a vast group of respondents. Applying this model to assess interoperability in a SC requires applying group-decision methods to combine different opinions of the same subject into one, to make a correct decision. 
The presence of inconsistency may be a theoretical problem since according to (Saaty, 1995), it is rather difficult to deal with inconsistency in pairwise comparisons matrices with dimension more than 9x9. In the case of the Alternative cluster relative do Lean interoperable practices, there are twelve different options and, so, should be a case of concern in this subject. However, in most cases the problem does not exist since firms will select a prior a sub-set of the practice as some of them are not relevant to their industrial context.

\section{Conclusions and Fut ure Work}

The design of a LARG Supply Chain consists in a strategic advance towards the global market but requires the ability to make decisions, adequate to the structure of the business and its business partners. The present paper provides two models that can aid managers to make decisions when applying Lean, Agile, Resilient and Green simultaneously, be ing able to establish preferable Practices and KPI's that are adequate to the needs of the main entities and their industrial partners within the SC. This set of Practices and KPI's will aid in the creation of an SCM inter-organizational information system that needs to be supported on an efficient and interoperable way. However, even conceiving an inter-organizational information system, often companies cannot guarantee an equal exchange of information between other entities. The second proposed model seek to make an assessment of the business interoperability, concerning with a LARG SCM system. This model evaluates the existing interoperability on the SC and establishes the most interoperable LARG Practices that should be applied when implementing a LARG methodology. The two models have been validated by SCM experts and application scenarios have been developed and simulated. Research work has identified sets of Practices and KPIs, and their relationships with LARG paradigms and competitiveness criteria. On-going research work is focusing on testing the models with data from automotive supply chains.

\section{Acknowledgment}

Authors would like to acknowledge Fundação para a Ciência e Tecnologia for funding the research work and providing scholarship grants to Izunildo Cabral and Pedro Cruz (MIT-Pt/EDAM-IASC/0033/2008).

\section{REFERENCES}

Agarwal, A., Shankar, R., \& Tiwari, M. K. (2006). Modeling the metrics of lean, agile and leagile supply chain: An ANP -based approach. European Journal of Operational Research, 173(1), 211-225.

Agarwal, A., Shankar, R., \& Tiwari, M. K. (2007). Modeling agility of supply chain. Industrial Marketing Management, 36(4), $443-457$.

ATHENA. (2006). Business Interoperability Framework. Retrieved from: http://modelbased.net/aif/methodology/bif.html

Azevedo, S. G., Carvalho, H., \& Machado, V. C. (2010). The Influence of LARG Supply Chain Management Practices on Manufacturing Supply Chain Performance (to be published)

Baramichai, M., Zimmers, E. W., \& Marangos, C. A. (2007). Agile supply chain transformation matrix: an integrated tool for creating an agile enterprise. Supply Chain Management-an International Joumal, 12(5), 334-348.

Berre, A.-J., Elveseter, B., Figay, N., Guglielmina, C., Johnsen, S., G., Lippe, S. (2005). ATHENA Interoperability Framework (AIF), website: http://modelbased.net/aif/methodology/bif.html

Fan, Q., Xu, X. J., \& Gong, Z. Y. (2007). Research on Lean, Agile and Leagile Supply Chain. 2007 International Conference on Wireless Communications, Networking and Mobile Computing, Vols 1-15, 4902-4905.

Huhns, M. N., Stephens, L. M., \& Ivezic, N. (2002). Automating supply-chain management. Paper presented at the Procedings of the first international joint conference on Autonomous agents and mult iagent system: part 3, Bologna, Italy.

Jardim-Goncalves, R., Grilo, A., \& Steiger-Garcao, A. (2006). Challenging the interoperability between computers in industry with MDA and SOA. Computers in Industry, 57(8-9), 679-689.

Legner, C., \& Wende, K. (2006). Towards an Excellence Framework for Business Interoperability. Paper presented at the 19th Bled eConference eValues, Bled, Slovenia. http://www.alexandria.unisg.ch/export/DL/66657.pdf

Rao, P., \& Holt, D. (2005). Do green supply chains lead to compet itiveness and economic performance? Intemational Journal of Operations \& Production Management, 25(9-10), 898-916.

Reichhart, A., \& Holweg, M. (2007). Lean distribution: concepts, contributions, conflicts. Intemational Joumal of Production Research, 45(16), 3699-3722.

Saaty, T. L. (1980). The Analytic Hierarchy Process: McGraw-Hill International Book Co.

Saaty, T. L. (1995). Decision making for leaders (3rd Edition ed.): RWS Publications.

Srivastava, S. K. (2007). Green supply-chain management: A state-of-the-art literature review. Intemational Joumal of Management Reviews, 9(1), 53-80.

Womack, J.P., Jones, D. T., \& Ross, D. (1991). The Machine That Changed the World: The Story of Lean Production: Harper Perennial.

Zutshi, A. (2010). Framework for a Business Interoperability Quotient Measurement Model. MSc - Master of Science, Universidade Nova de Lisboa, Almada. Retrieved from http://run.unl.pt/handle/10362/2646 